\title{
Shallow Water Simulation of Overland Flows in Idealised Catchments
}

\author{
Dr. Dongfang Liang (corresponding author)
}

Tel: +44 1223 764829; E-mail: d.liang@eng.cam.ac.uk

Department of Engineering, University of Cambridge, Cambridge CB2 1PZ, UK

Mr. Ilhan Özgen

Tel: +49 30 31472428; E-mail: ilhan.oezgen@wahyd.tu-berlin.de

Chair of Water Resources Management and Modeling of Hydrosystems, Technische Universität Berlin, Berlin, Germany

Prof. Reinhard Hinkelmann

Tel: 4930 31472307; E-mail: reinhard.hinkelmann@wahyd.tu-berlin.de

Chair of Water Resources Management and Modeling of Hydrosystems, Technische Universität Berlin, Berlin, Germany

Prof. Yang Xiao

$\underline{\text { sediment_lab@hhu.edu.cn }}$

State Key Laboratory of Hydrology-Water Resources and Hydraulic Engineering, Hohai University, Nanjing 210098, China

\author{
Dr. Jack M. Chen \\ jack.m.chen@gmail.com
}

Department of Engineering, University of Cambridge, Cambridge CB2 1PZ, UK 


\begin{abstract}
This paper investigates the relationship between the rainfall and runoff in idealised catchments, either with or without obstacle arrays, using an extensively-validated fullydynamic shallow water model. This two-dimensional hydrodynamic model allows a direct transformation of the spatially distributed rainfall into the flow hydrograph at the catchment outlet. The model was first verified by reproducing the analytical and experimental results in both one-dimensional and two-dimensional situations. Then, dimensional analyses were exploited in deriving the dimensionless S-curve, which is able to generically depict the relationship between the rainfall and runoff. For a frictionless plane catchment, with or without an obstacle array, the dimensionless Scurve seems to be insensitive to the rainfall intensity, catchment area and slope, especially in the early steep-rising section of the curve. Finally, the model was used to study the hydrological response of an idealised catchment covered with buildings, which were represented as an obstacle array. The influences of the building array size and layout on the catchment response were presented in terms of the dimensionless time at which the catchment outflow reaches $50 \%$ of the equilibrium value.
\end{abstract}

Key words: Shallow water equations; rainfall-runoff; overland flows; dimensional analysis; pluvial flooding; urban flooding

\title{
1. Introduction
}

The relationship between rainfall and runoff is a fundamental hydrological problem. The total precipitation less the amount of water due to interception, infiltration, evapotranspiration, etc. contributes to the flow over the ground, which runs off quickly 
to rivers. The surface runoff is the most dynamic part of the response of a watershed to the rainfall, causing soil erosion and non-point source pollution. Early studies on the rainfall-induced overland flows rely largely on empirical formulae acquired from statistical analyses of past hydrological data. The lumped unit hydrograph theory assumes a linear response of the watershed outflow to the rainfall. Although it is still taught in the university level, such an unreasonable assumption casts doubt on its validity.

With the development of computing techniques and mathematical models, more and more distributed physically-based methods have been proposed. Notable efforts have been devoted to resolve the water depths and flow velocities by means of sophisticated hydrodynamic descriptions of the overland flow phenomena. Because the surface runoff is most of the time confined in a thin layer with large horizontal extents, the shallow water equations are able to model these flows accurately. In the context of overland flow studies, Zhang and Cundy (1989) are among the first to solve the twodimensional (2D) fully-dynamic shallow water equations with a finite difference scheme, and they found the importance of ground micro-topography to the overland flow. In recent years, there has been an increasing trend of extending the application of the shallow water equations to the city and catchment scales (e.g., Unami et al. 2009; Mügler et al. 2011; Caviedes-Voullième et al., 2012; Costabile et al., 2013; Simons et al. 2014).

The solution of the fully-dynamic shallow water equations is computationally demanding, which restricts the high-resolution simulation over a large area. As a consequence, various simplifications were more commonly used in the past, including the kinematic wave and diffusive wave models (Woolhiser and Liggett 1967; Di 
Giammarco et al. 1996; Feng and Molz 1997; Kazezyilmaz-Alhan and Medina 2007;

Gottardi and Venutelli 2008). The diffusive wave model neglects the inertia of the fluid in the momentum equations. The kinematic wave model further neglects the effect of pressure gradient on the water motion. Lots of studies can be found concerning their applicability in various conditions (Woolhiser and Liggett 1967; Moramarco and Singh 2002; Tsai 2003). These models were often validated against small-scale laboratory experiments, where catchments and hillslopes were idealised into simple plane surfaces with constant hydraulic properties. However, rapidly varying flows due to sudden changes in topography cannot be handled properly by these simplified models (Yeh et al. 2011, Costabile et al. 2012). In scenarios where the flow is not dominated by the bed friction, the catchment runoff should be modelled using the full shallow water equations (Thompson et al. 2010).

With the increasing urbanisation and the need for combating flash surface water floods, it has become increasingly important to understand the influence of buildings or obstacles on the rainfall-runoff relationship (Schubert and Sanders 2012). In contrast to plenty of studies on fluvial flooding and the rainfall-runoff over plane slopes, both experimentally and numerically, there has been very limited research on the role played by buildings on the catchments' response to intensive rainfalls. Short-lived storms often cause severe damages in cities, where the ground is paved with little friction and permeability, population density is high, and economic activities are concentrated. More frequent extreme weather events will certainly bring more intense localised precipitation and thus floods to cities.

This paper reports on a numerical investigation of the hydrological response of idealised catchments, which are occupied by regular obstacle arrays representing 
buildings. A Total Variation Diminishing (TVD) computational method, named TVDMacCormack scheme, has been employed to seek the numerical solutions to the nonlinear shallow water equations. Spatially-distributed precipitation over the catchment is introduced via the source term in the continuity equation. The computational model is first verified against experimental measurements and analytical solutions. Then, dimensional analysis is conducted to find out suitable dimensionless groups to summarise the rainfall-runoff relationship in a generic fashion. Finally, the dependence of the rainfall-runoff relationship on the building array dimension and layout is investigated through parametric studies.

\section{Mathematical Model}

\subsection{Shallow water model}

The fully-dynamic non-linear shallow water equations are used to model the rainfallrunoff processes. Because of the much greater horizontal extent of the surface runoff than the water depth, the application of this depth-averaged modelling approach is appropriate. The three unknown functions are governed by the following three partial differential equations, which describe the conservation of mass and momentum. This study assumes the catchment to be impermeable and also ignores evaporation.

$$
\begin{gathered}
\frac{\partial \eta}{\partial t}+\frac{\partial q_{x}}{\partial x}+\frac{\partial q_{y}}{\partial y}=i \\
\frac{\partial q_{x}}{\partial t}+\frac{\partial\left(q_{x}{ }^{2} / H\right)}{\partial x}+\frac{\partial\left(q_{x} q_{y} / H\right)}{\partial y}=-g H \frac{\partial \eta}{\partial x}-\frac{n^{2} g q_{x} \sqrt{{q_{x}{ }^{2}+q_{y}{ }^{2}}^{7 / 3}}}{H^{7 / 3}} \\
\frac{\partial q_{y}}{\partial t}+\frac{\partial\left(q_{x} q_{y} / H\right)}{\partial x}+\frac{\partial\left(q_{y}{ }^{2} / H\right)}{\partial y}=-g H \frac{\partial \eta}{\partial y}-\frac{n^{2} g q_{y} \sqrt{q_{x}{ }^{2}+q_{y}{ }^{2}}}{H^{7 / 3}}
\end{gathered}
$$


where $t$ is time; $x$ and $y$ are the two horizontal Cartesian coordinates; $\eta$ is the water surface elevation; $q_{x}$ and $q_{y}$ are the volumetric discharges per unit width in the $x$ and $y$ directions, respectively; $n$ is the Manning's roughness coefficient; $H$ is the total water column depth; $g$ is the acceleration due to gravity; $i$ is the rainfall intensity, which is quantified as the flow rate per unit plan-surface area. This study assumes that the rainwater joins the surface water vertically, hence ignores their momentum exchange in the horizontal directions. These shallow water equations can also be expressed in the vector form and in various conservative formulations, the details of which can be found in Liang et al. (2006, 2007).

\subsection{Computational techniques}

A highly efficient Total Variation Diminishing (TVD) MacCormack scheme has been applied to numerically solve the above non-linear shallow water equations. This scheme consists of a predictor step, a corrector step and a TVD modification step, and is of second order accuracy in both time and space. It has been extensively verified in such applications as flood routing in river valleys (Liang et al. 2007), tsunami wave propagation and runup (Liang et al. 2010), water quality modelling (Liang et al. 2012), and tidal oscillations in estuaries and harbours (Liang et al. 2014). This numerical scheme is not herein repeated, as the main purpose of the present study is the physics of the rainfall-induced runoff process. Readers are referred to Liang et al. $(2006,2007)$ for the full implementation of the core numerical scheme, as well as the key numerical treatments regarding wetting/drying, adaptive time stepping, the inclusion of bed resistance at very small water depths, etc. 
Some catchments analysed in this study contain buildings, so an appropriate method of representing buildings is necessary. Cea et al. (2010) and Chan (2012) compared four methods of representation, namely the building-hole method, building-block method, increased-roughness method and porous-medium method. The building-hole method was found to perform best in balancing the numerical accuracy and stability, and is thus adopted in the subsequent applications. In this method, the buildings/obstructions are excluded from the computational domain; the imposed rainfall intensity over the computational domain is increased to compensate the neglected rain falling on top of the buildings. This method does not account for the momentum of the water running down the edges of the buildings, because only the horizontal momentum is taken into account in the shallow water equations. For buildings with vertical sidewalls, the rainwater falling on them eventually runs down vertically to the ground and thus does not possess horizontal momentum. This study does not consider the situations where the sidewalls are not vertical or the drainpipes guide the rainwater from the roof to reach the ground non-vertically.

In most of the rainfall-runoff experiments, water running out of the test domain at the end of the catchment undergoes a free-fall to the downstream reservoir. This mimics the real situation where a steep-banked stream often forms at the bottom of a hill slope. If the flow inside the domain is subcritical, it can be assumed that the flow at outlet of the catchment is critical, so the flow velocity is equal to the shallow-water wave celerity. If the flow upstream of the boundary is supercritical, then no downstream boundary condition is needed. In the computation, such a complicated boundary condition can be executed by adding a short steep slope downstream of the actual catchment. In the case of subcritical flows, the ground slope change triggers the transition from subcritical 
flow to supercritical flow, ensuring the critical flow condition at the location of the slope change; in the case of supercritical flows, the extra steep slope helps maintain the supercritical condition, thus the downstream boundary does not exert any influence on the flow inside the domain.

\section{Model Verification}

\subsection{Constant rainfall over a one-dimensional (1D) slope}

For this widely-used verification example, Gottardi \& Venutelli (2008) compared computed results with analytical solutions and experimental results obtained in Morgali \& Linsley (1965). The experimental domain is a turf plane of length $L=21.945 \mathrm{~m}$ and slope $S_{b}=0.04$. Two experiments were carried out. In the first case, a uniform rainfall intensity $i=2.58233 \times 10^{-5} \mathrm{~m} / \mathrm{s}$ was imposed on the slope of Manning's roughness coefficient $n=0.5 \mathrm{~m}^{-1 / 3} \mathrm{~s}$. In the second case, a uniform rainfall $i=1.33350 \times 10^{-5} \mathrm{~m} / \mathrm{s}$ was imposed with $n=0.4 \mathrm{~m}^{-1 / 3} \mathrm{~s}$. The large roughness coefficients are a reflection of the very rough turf plane used. In both cases, the rainfall was unceasing, and the simulation time of $1200 \mathrm{~s}$ was longer than the time of concentration of the slope, so that equilibrium hydrograph was reached towards the end of the simulation. The grid size and time step used were $\Delta x=0.25 \mathrm{~m}$ and $\Delta t=0.5 \mathrm{~s}$, respectively. 


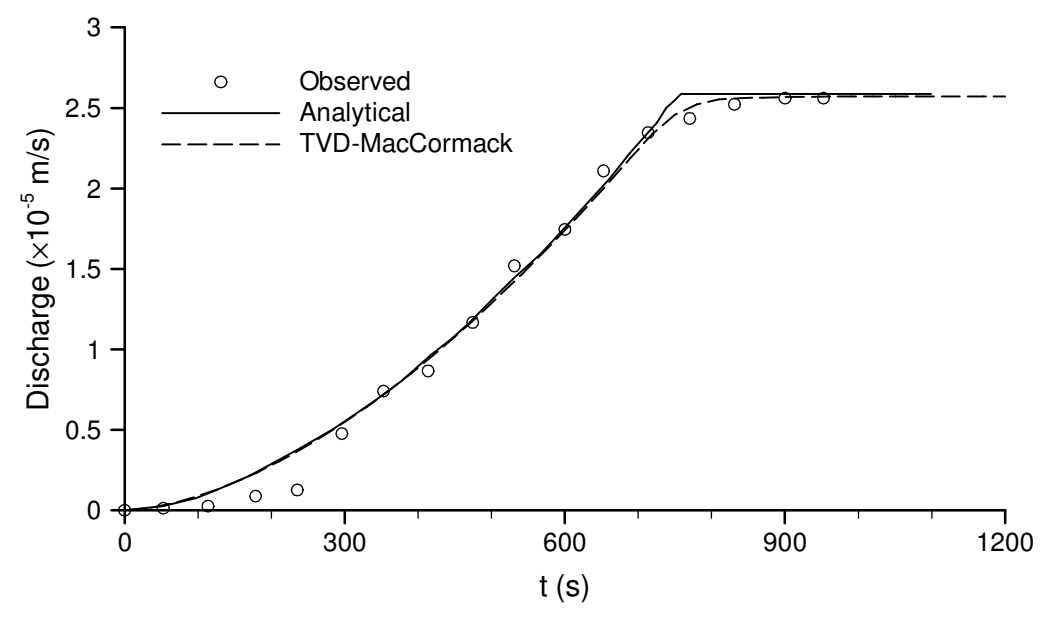

(a) $i=2.58233 \times 10^{-5} \mathrm{~m} / \mathrm{s}$

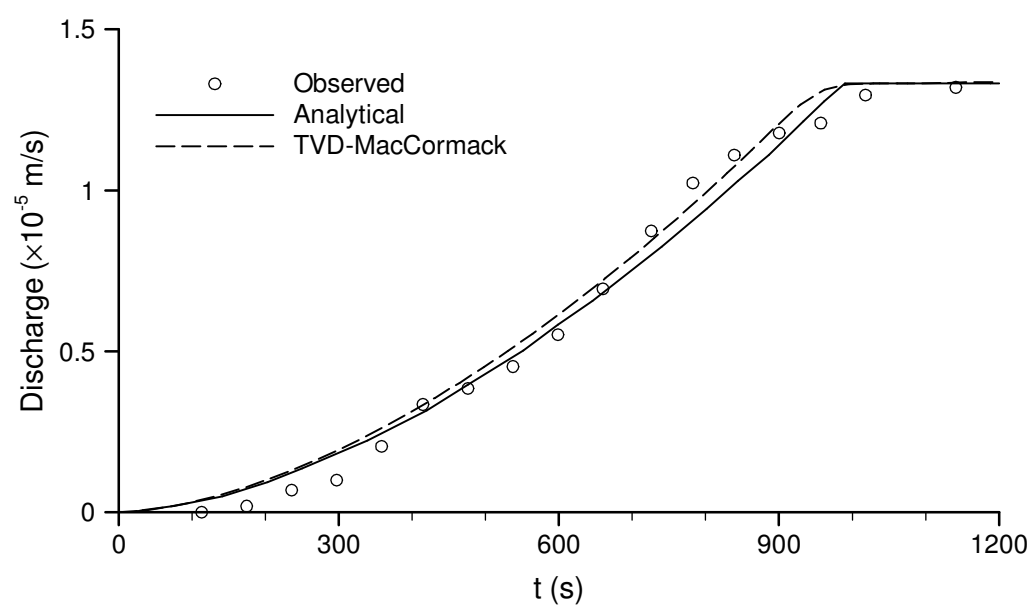

(b) $i=1.33350 \times 10^{-5} \mathrm{~m} / \mathrm{s}$

Figure 1. Hydrographs for constant rainfalls over a 1D slope

The experimental, analytical and computational runoff hydrographs obtained for the two cases are all shown in Figure 1. To be consistent with the presentation of Morgali \& Linsley (1965) and Gottardi \& Venutelli (2008), the outflow rate at the downstream end of the slope has been divided by the area of the plane, so that the runoff has the same units as the rainfall in Figure 1. In the equilibrium stage, the runoff should then be of exactly the same value as the rainfall input. 
In the first case, the simulation results correspond well with both the analytical and experimental results. The slower experimental flow initially could be due to the rainwater being intercepted by the grass or being absorbed by the ground (Gottardi \& Venutelli, 2008). A similar discrepancy is observed in the simulation carried out by Gottardi \& Venutelli (2008). The simulation result obtained in the second case is not as accurate as in the first case, with a slightly faster flow compared to the analytical and experimental results. As the smaller rainfall corresponds to a smaller flow speed and a smaller water depth, the numerical error associated with the wetting/drying algorithm and the uncertainty with the bed roughness tend to be more pronounced. However, the overall computational accuracy is satisfactory in both cases.

For continuous rainfall of constant intensity uniformly distributed over an impervious basin, the time needed to reach the equilibrium discharge is called the time of concentration. It can be roughly deemed to be the time taken for a raindrop falling on the furthest part of the basin to flow down to the outlet. Once that furthest part of the catchment starts contributing to the flow at the outlet, then all parts of the basin are contributing. Figure 1 indicates that the time of concentration increases with the decrease of the rainfall intensity.

\subsection{Variable rainfall over a 1D slope}

Govindaraju et al. (1988, 1990) and Gottardi and Venutelli (2008) considered the situations in which the rainfall intensity was uniform over the entire domain but varied with time. The plane considered has a length $L=22 \mathrm{~m}$. For the two cases selected in the present study, the Chézy roughness coefficient $C=1.767 \mathrm{~m}^{1 / 2} / \mathrm{s}$, and the slope $S_{b}=$ 
0.04. The input rainfall histories in the two cases are tabulated in Table 1. In both cases, the grid size was $\Delta x=0.25 \mathrm{~m}$ and the time step was $\Delta t=0.5 \mathrm{~s}$.

Table 1. Rainfall histories in the two test cases taken from Govindaraju et al (1990)

\begin{tabular}{|c|c|c|c|c|c|}
\hline Time (min) & $0-10$ & $10-20$ & $20-30$ & $30-40$ & $\ldots$ \\
\hline Rainfall in Case 1 $\left(10^{-5} \mathrm{~m} / \mathrm{s}\right)$ & 1.41 & 2.82 & 1.41 & 2.82 & 0 \\
\hline Rainfall in Case $2\left(10^{-5} \mathrm{~m} / \mathrm{s}\right)$ & 2.82 & 1.41 & 2.82 & 1.41 & 0 \\
\hline
\end{tabular}

The hydrographs obtained for the two cases are shown in Figure 2. The simulation results compare very well with the approximate analytical solutions for overland flows given in Govindaraju et al. (1990). Both the peak runoff and the overall shape match well with the analytical solutions. Similar results were also presented in Gottardi \& Venutelli (2008), which solved a diffusive wave model and a kinematic wave model with an integration scheme. In these two cases, the total amount of the rainfall is the same, so the results emphasise the importance of the rainfall distribution to the runoffs generated.

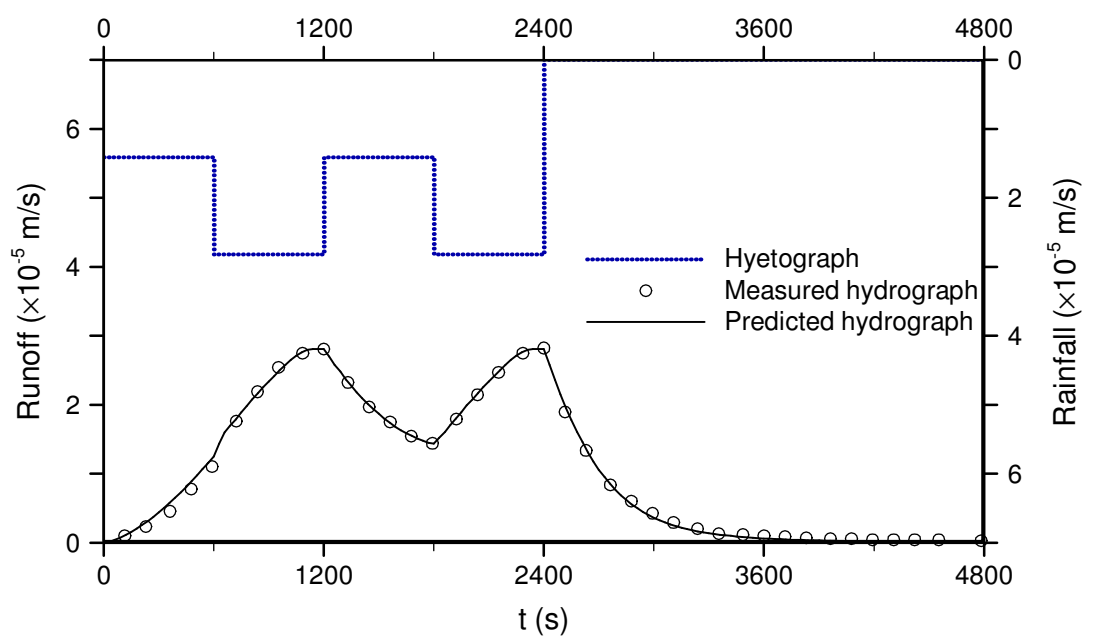

(a) Case 1 


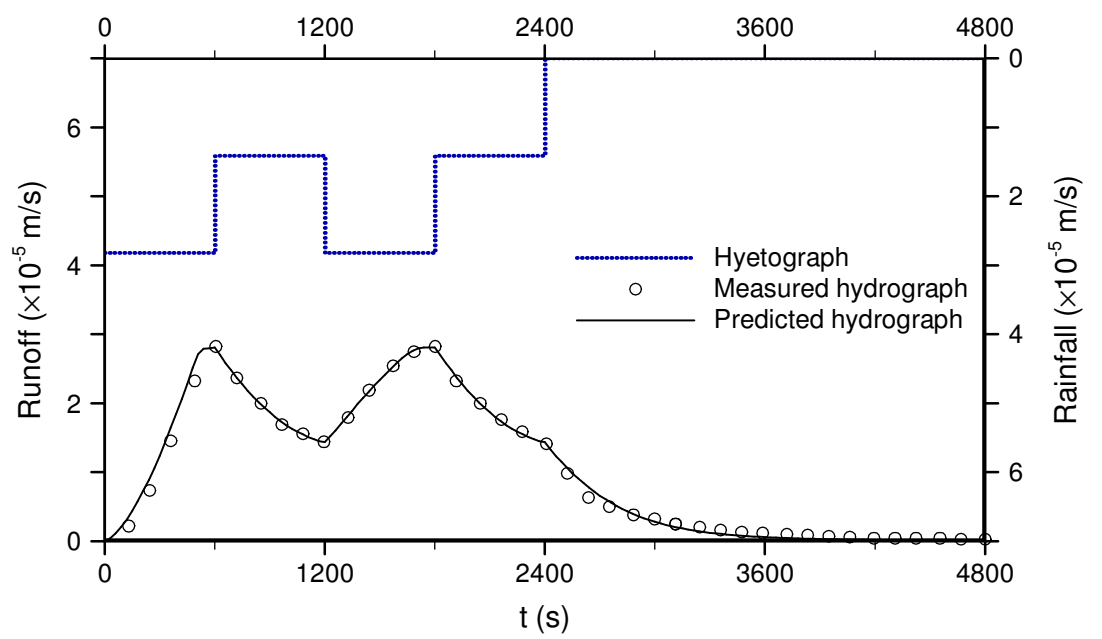

(b) Case 2

Figure 2. Hydrographs of variable rainfalls over a 1D slope

\subsection{Rainfall over a 2D catchment}

Cea et al. (2008) conducted laboratory experiments to study the shallow water flow generated by a uniform rainfall over a simple 2D geometry. The model consists of 3 stainless steel planes each with a slope of 0.05 , which are connected to form a watercollection channel in the middle of a $2 \times 2.5 \mathrm{~m}^{2}$ rectangular basin, as seen in Figure 3 . To increase the complexity of the problem, two oblique high walls were added to the basin, which are signified by the thick white lines in Figure 3. The Manning's roughness coefficient is $0.009 \mathrm{~m}^{-1 / 3} \mathrm{~s}$. Rainfall was produced using a grid of 100 uniformly distributed nozzles over the entire basin, and the hydrograph at the system outlet was measured. Three scenarios with differing rainfall intensities were investigated. In the first case, a rainfall intensity of $317 \mathrm{~mm} / \mathrm{h}$ was applied for $45 \mathrm{~s}$; in the second case, $320 \mathrm{~mm} / \mathrm{h}$ rainfall was first applied for $25 \mathrm{~s}$, stopped for $4 \mathrm{~s}$, and reapplied for another $25 \mathrm{~s}$; in the last case, $328 \mathrm{~mm} / \mathrm{h}$ rainfall was applied for $25 \mathrm{~s}$, stopped for $7 \mathrm{~s}$ before being reapplied for another $25 \mathrm{~s}$. 


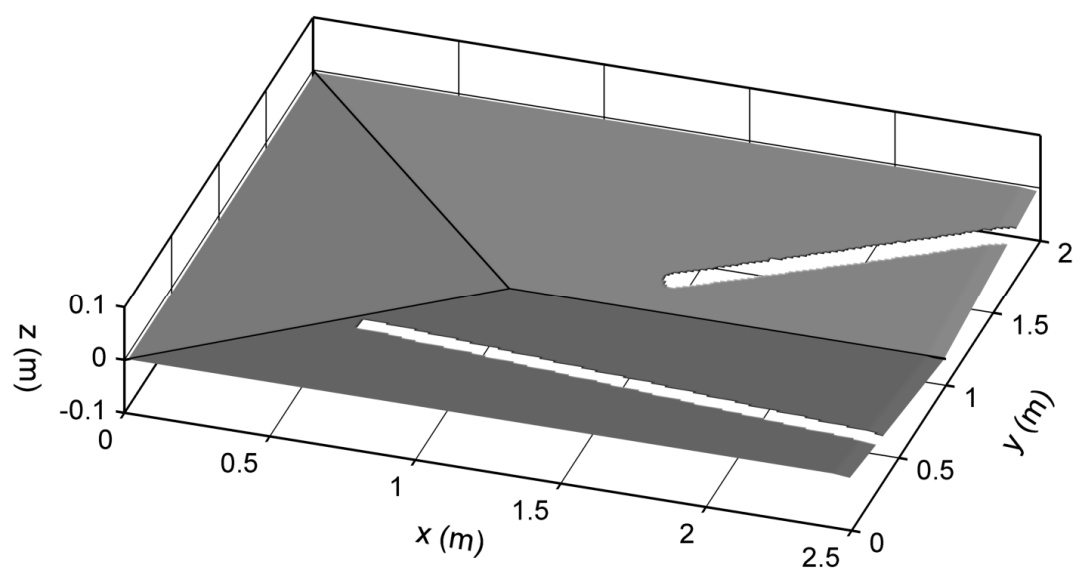

Figure 3. Catchment shape studied in Cea et al. (2008)

In the simulations, the grid size was set at $0.01 \mathrm{~m}$ in discretising the entire surface area. The so-called building-hole method was used, thus the grid cells representing the walls were excluded from the computation. To compensate the rain falling on these grid cells in the simulations, the rainfall intensity applied to other locations was increased by the ratio between the area occupied by the walls and the total catchment area. At the right boundary, the flow underwent a free fall after running out of the domain; at the other three boundaries, the solid wall condition was specified. Figure 4 illustrates four snapshots of the predicted water depth distributions and velocity fields in Case 1. By comparing the water surface level with the bed elevation at various locations, the current simulations are found to be rational. Figure 4(a) shows the moment when the accumulation of water in the central channel has not been established 5 seconds after the start of the rain, and there is little outflow from the catchment. Apparent collection of water in the central channel is observed 20 seconds into the rainfall. As shown in Figure 4(b), the water depths and velocities have apparently increased in front of the solid walls and along the central channel. Figure 4(c) indicates little difference to the flow features shown in Figure 4(b), although water in the central part of the catchment becomes deeper. Figures 4(a-c) suggest that the flow across the 
three slopes do not change much during the rainfall. The rainwater runs down the steepest slope and converges into streams at plane connections. Almost immediately after the rain stops, the flow over the upper part of the plane disappears, as seen in Figure 4(d). Because of the steep slope and smooth surface, the catchment responds to the rainfall rapidly.

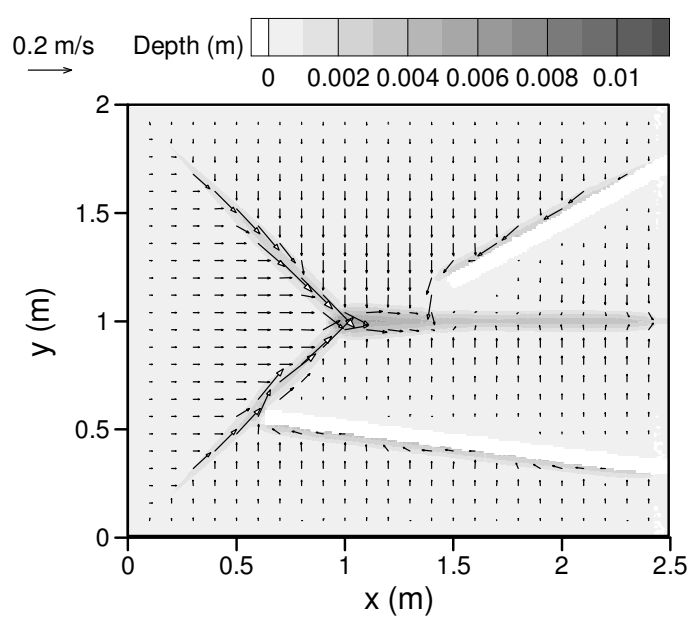

(a) $t=5 \mathrm{~s}$

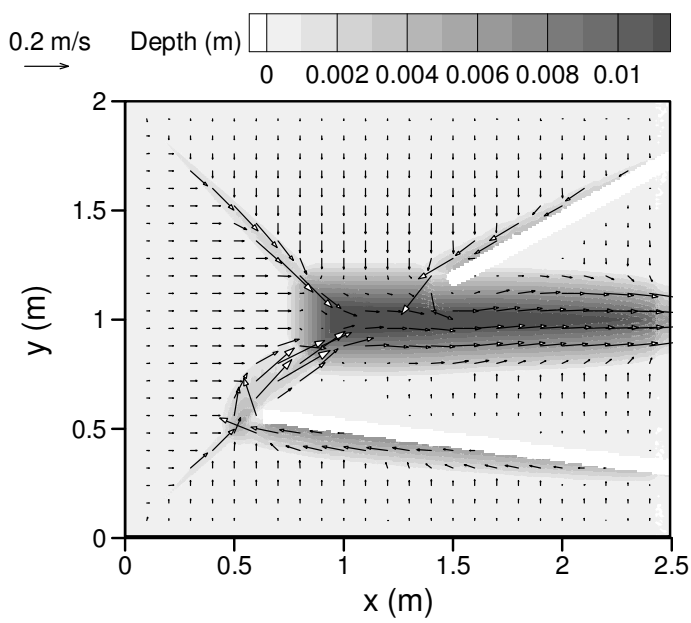

(c) $t=45 \mathrm{~s}$

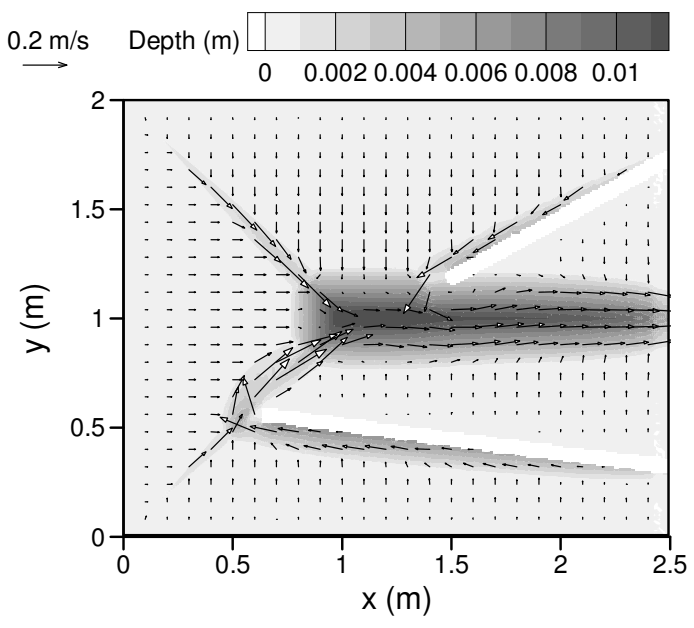

(b) $t=20 \mathrm{~s}$

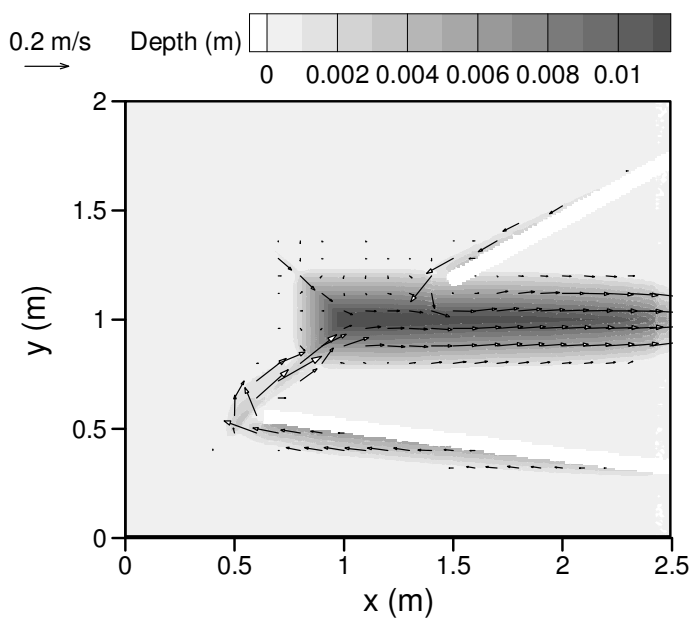

(d) $t=50 \mathrm{~s}$

Figure 4. Snapshots of the water depth distributions and velocity fields in Case 1

The output hydrographs of the simulations and experiments for all three cases are plotted in Figure 5, together with the corresponding hyetographs. The shapes of the 
hydrographs have been very well predicted, although there is slight mismatch in terms of the peak flow rates. According to the results for Case 1, the time of concentration is more than $45 \mathrm{~s}$, so that the hydrograph does not plateau during the $45 \mathrm{~s}$ of rainfall. In Cases 2 and 3, the discharge increases until the rainfall is stopped at $25 \mathrm{~s}$. Thereafter, it decreases immediately. When the rainfall is restarted after $4 \mathrm{~s}$ and $7 \mathrm{~s}$, respectively, the discharge continues to decrease for a few seconds before increasing again, which is due to the time taken for the rainwater falling inside to reach the catchment outlet.

Although there are some discrepancies, the agreement between the experimental and simulation results can be deemed as satisfactory considering the complexity of the domain and some uncertainties with the experiments. Numerical simulations carried out by Cea et al. (2008) produced similar results, where a few experimental uncertainties were pointed out that might cause the disparities between the measured and predicted results. Firstly, the rainfall intensity provided by the nozzles might not be uniformly distributed. Secondly, surface tension might prevent water movement at very shallow depths. Thirdly, the nozzle response had a small time lag when the rainfall intensity increased from zero to the maximum value, which explains the slight overprediction of the flow rate in the first few seconds. Finally, some nozzles still leaked a bit after the rainfall had ceased, which explains the slight underprediction of the flow rate in the falling limb of the hydrograph. 


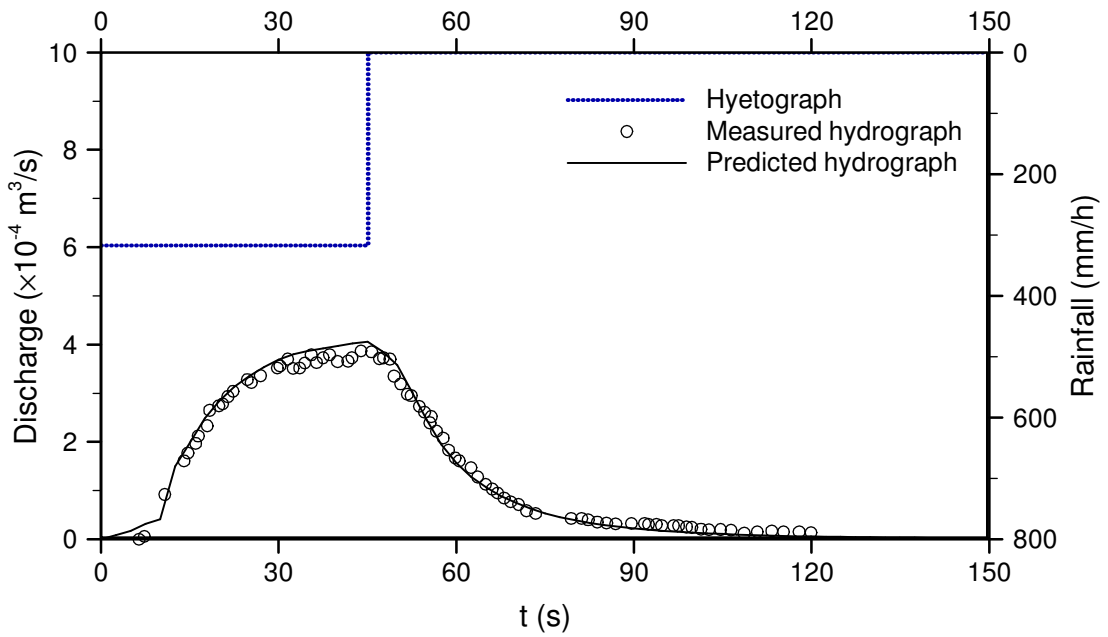

(a) Case 1

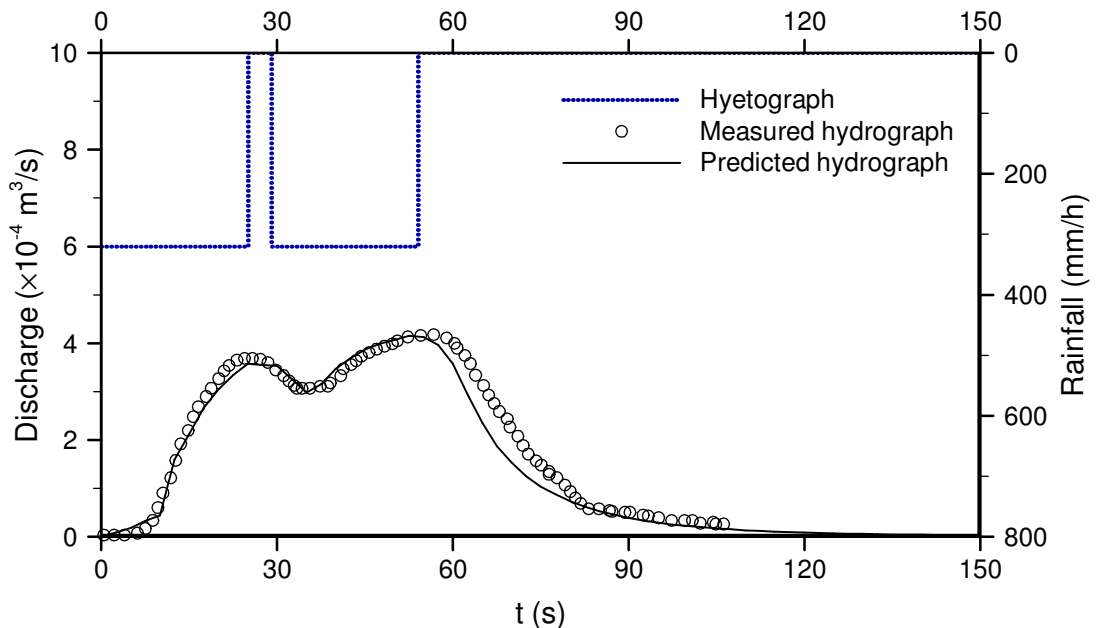

(b) Case 2

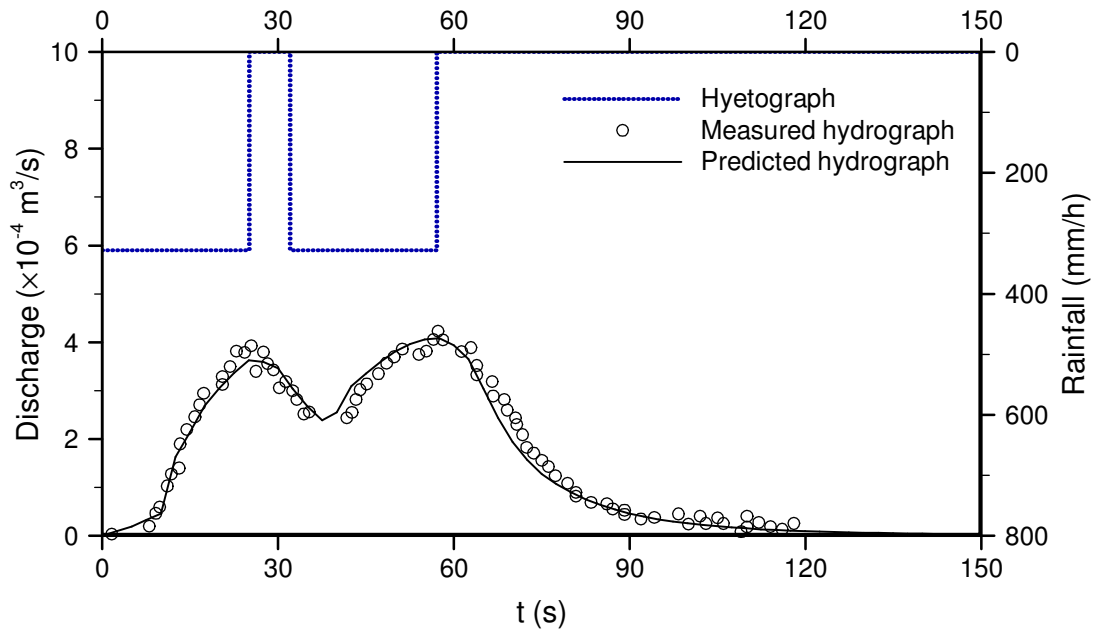


(b) Case 3

Figure 5. Hydrological response of the catchment in the $2 \mathrm{D}$ verification

\section{Model Application}

\subsection{Dimensional analysis of the catchment response to unceasing uniform rainfall}

By normalising the parameters influencing the rainfall-runoff processes over an idealised catchment, we are able to generalise the conclusions drawn from specific numerical simulations. As the starting point, we consider the unceasing uniform rain falling on frictionless 1D slopes. The frictionless assumption removes the need for any roughness parameters in the mathematical definition of the problem. In the context of urban flooding, the ground is indeed relatively smooth, but the rapid flow with a small depth may still be significantly influenced by the ground roughness. However, friction always slows down the flow, thus the results derived from the frictionless plane provides a limit for the real-world phenomena. The reason for considering the unceasing uniform rainfall is that there is no time scale attached to it. With these simplifications, the independent variables relevant to the hydrological response of the catchment includes: the rainfall intensity $i$ with units of $\mathrm{m} / \mathrm{s}$, the length of the catchment $L$ with units of $\mathrm{m}$, the slope of the catchment $S_{b}$ which is dimensionless, the gravitational acceleration $g$ with units of $\mathrm{m} / \mathrm{s}^{2}$, and the unit-width flow rate at the outlet of the catchment $q$ with units of $\mathrm{m}^{2} / \mathrm{s}$. The hydrographs generated by unceasing uniform rainfalls are actually $\mathrm{S}$-curves. With the properly-constructed dimensionless flow rate and dimensionless time, we expect the S-curves for different combinations of the catchment and rainfall parameters to collapse to a single dimensionless curve.

The dimensionless flow rate can be easily taken to be 


$$
Q^{*}=\frac{q}{L \cdot i}
$$

which ranges from 0 to 1 . It is simply the ratio between the unit-width outflow from the catchment and the unit-width influx of rainwater to the catchment. This normalised flow rate reaches 1 at the time of concentration, when the flow into and the flow out of the domain are equal and the flow inside the domain maintains a steady state.

The time of concentration, $t_{c}$ with units of $\mathrm{s}$, is an indicator of the shape of a S-curve. A small $t_{c}$ implies a steep rise of the outflow from 0 to the equilibrium value, and vice versa. By normalising $t_{c}$, we actually non-dimensionalise the time so that the nondimensional S-curve becomes independent of the rainfall intensity, catchment size, etc. The time can be made non-dimensional in multiple ways using different combinations of other independent variables. One way is based on the rainfall intensity and the length of the catchment:

$$
t^{*}=\frac{t \cdot i}{L}
$$

As will be seen later, this is too much of a simplification and does not produce collapsed S-curves for any of the simulations. The other more physically-sound way resorts to the catchment length, slope and gravitational acceleration, upon which the timescale of the runoff truly relies.

$$
t^{*}=\frac{t \cdot \sqrt{S_{b} \cdot g}}{\sqrt{L}}
$$

In the above formula, $\left(S_{b} \cdot g\right)$ is the component of the gravitational acceleration along the slope that drives the flow. Unlike the first way, the second way ignores the influence of the rainfall intensity on the shape of the S-curve, which causes some difficulties in obtaining a truly unique dimensionless S-curve. 
In a study relevant to the present paper, Woolhiser and Liggett (1967) examined the difference between the dynamic-wave model and the kinematic-wave model in predicting the rising hydrograph over a uniform slope, which are basically S-curve of the plane catchment. Similarly, Gottardi and Venutelli (2008) proposed an accurate time integration method for the diffusive-wave and kinematic-wave models and applied it to predict the rising hydrographs of overland flows. However, those studies are not applicable to frictionless catchments, where the flow inertia plays a dominant role. In those studies, the time and other variables were normalised using the normal depth, normal speed and Chézy coefficient, which are nonexistent if the bed is frictionless. Hence, the non-dimensional time in this study takes on a different form from that in previous studies.

\subsection{Rainfall-runoff on uniform slopes with and without building arrays}

In this basic set of simulations, the domain is discretised into 243 grid points in the $x$ direction and 243 grid points in the $y$ direction. The flow is $1 \mathrm{D}$, and the $y$-direction velocity is actually zero in this case. Hence, the length of the domain in the $x$ direction should be used in calculating the dimensionless flow rate and dimensionless time. The reason for choosing a square domain for the $1 \mathrm{D}$ simulation is its ease of adding building arrays over the domain, which will be examined in the next session. A large number of simulations were conducted, with different combinations of the rainfall intensity, domain size and domain slope. Figure 6(a) shows the hydrographs of six situations. The large ranges of the tested rainfall intensity, catchment size and slope result in significant disparities among the curves, in terms of the maximum discharge and the time taken to reach the maximum discharge. 
The time and unit-width discharge are then normalised according to the aforementioned dimensional analysis. When using the quantity $t^{*}=t \cdot i / L$ as the dimensionless time, it is clear from Figure 6(b) that this way of normalisation is unable to collapse the curves together. Taking the dimensionless time to be $t^{*}=t \cdot \sqrt{S_{b} \cdot g / L}$, the S-curves with different rainfall intensities, catchment sizes and slopes all converge to a seemingly unique relationship. The scaled S-curves follow almost the same shape at the early rising stage of the hydrographs. Some differences are obvious when these normalised S-curves gradually approach the equilibrium flow rates, which may be attributed to the disregard of the rainfall intensity in the time normalisation. With the same catchment size and slope, a heavier rainfall leads to a deeper water layer over the catchment at the equilibrium stage, hence a greater volume of water inside the catchment. On the plots in Figure 6, the area between the S-curve and the horizontal line, along which the flow rate is equal to the equilibrium value, represents the volume of water stored in the catchment. Based on the above analysis, this area should be larger for a heavier rainfall. Therefore, we cannot expect the dimensionless S-curves to fully coincide with one another.

The speed of the S-curve rise can be quantified by the time of concentration $t_{c}$. In reality, however, it is impractical to use the full time of concentration, which is the time taken for the flow rate to rise from zero to the equilibrium value. Because the flow rate often approaches the equilibrium value very slowly, the determination of the full time of concentration involves large errors and its magnitude cannot truly reflect the overall speed of the flow rate increase. In this consideration, this study adopts $t_{50}$, which is the time taken for the flow rate to rise to $50 \%$ of the equilibrium flow rate, to represent the overall rate of the discharge increase and thus the time scale of the hydrograph. From 
Figure 6(c), it is seen that the dimensionless time scales of the S-curves are roughly the same with $t_{50}{ }^{*} \approx 1.0$, and this value is generic for all the frictionless uniform slopes.

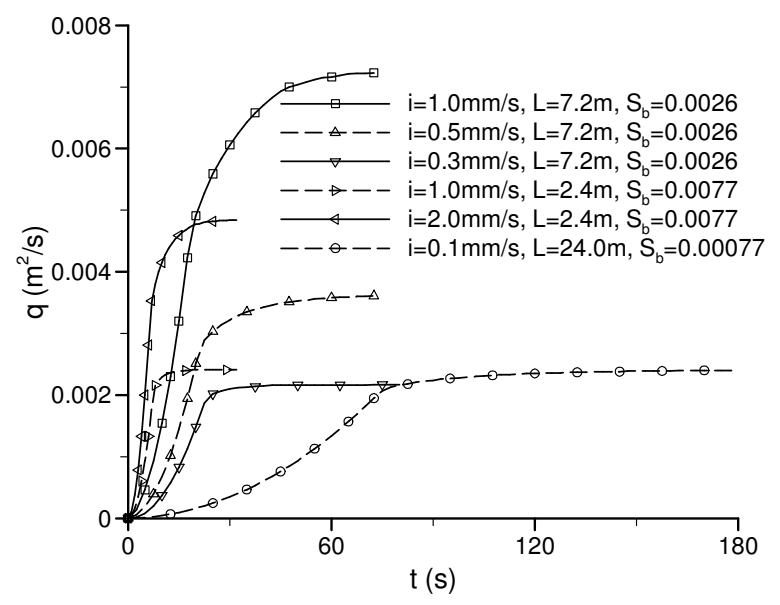

(a) Unit-width discharges vs. time

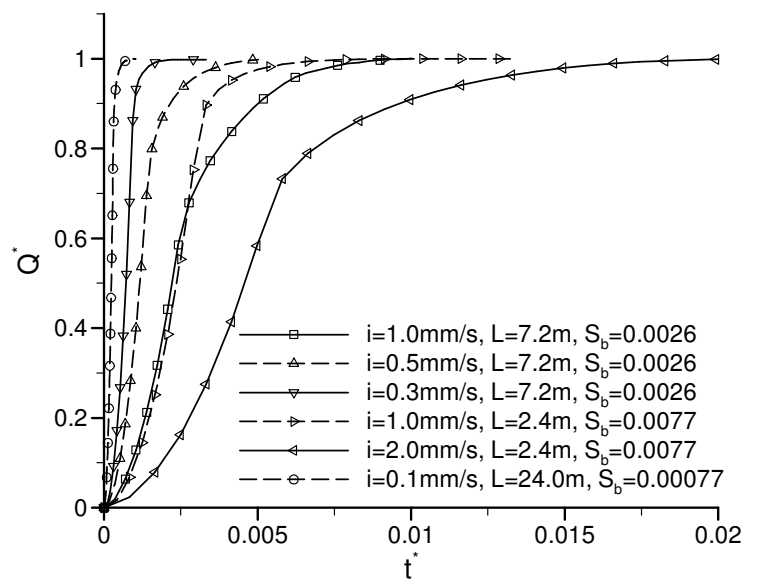

(b) Dimensionless hydrograph with $t^{*}=t \cdot i / L$ 


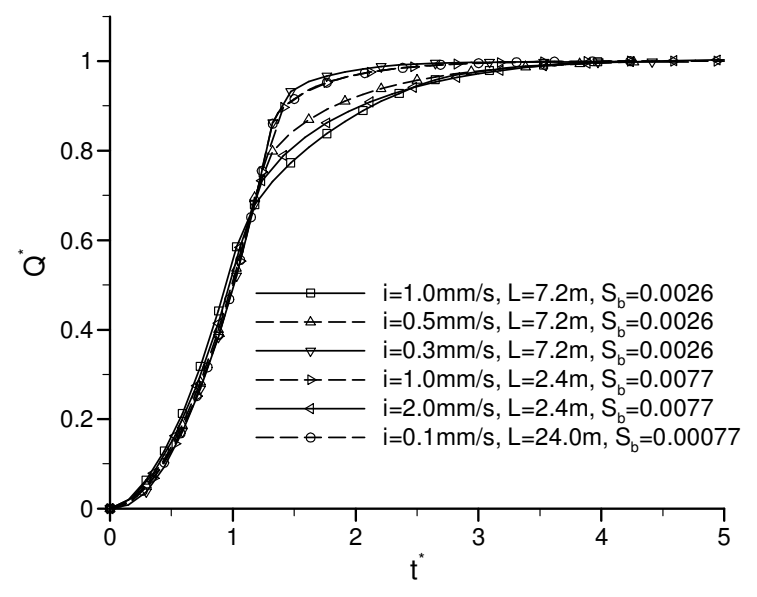

(c) Dimensionless hydrograph with $t^{*}=t \cdot \sqrt{S_{b} \cdot g / L}$

Figure 6. S-curves for frictionless uniform slopes

The same simulations are now repeated with an array of buildings in the domain. The array consists of 10 rows and 10 columns, and the buildings are in regular in-line pattern. All individual buildings in the array are of the same size and of square shape. In Figure 7(a), the buildings are represented by the blue square blocks. The total area occupied by the buildings is $25 \%$ of the total area of the catchment, so the gap between two neighbouring buildings is approximately equal to the building width. The aforementioned building-hole method is used to handle the presence of buildings. There is no slope in the background elevations in the $y$ direction and the buildings take on a repetitive pattern, so the gross flow can still be regarded as 1D. However, the localised flow around individual buildings contains the $y$-direction velocity component.

In order to avoid too many figures in this paper, the original S-curves with units are not shown. Only the dimensionless S-curves with $t^{*}=t \cdot \sqrt{S_{b} \cdot g / L}$ are shown in Figure 7(b). The curves collapse together nicely, which clearly verifies that the dimensional arguments are still valid with the inclusion of building arrays. With the 
presence of a regular building array that in total occupies $25 \%$ of the catchment area, the dimensionless time scale of the S-curve rise is around $t_{50}{ }^{*} \approx 1.4$, which is independent of the rainfall intensity, catchment size and slope. In comparison with the results obtained without the presence of buildings, the dimensionless time scale increases by $40 \%$.

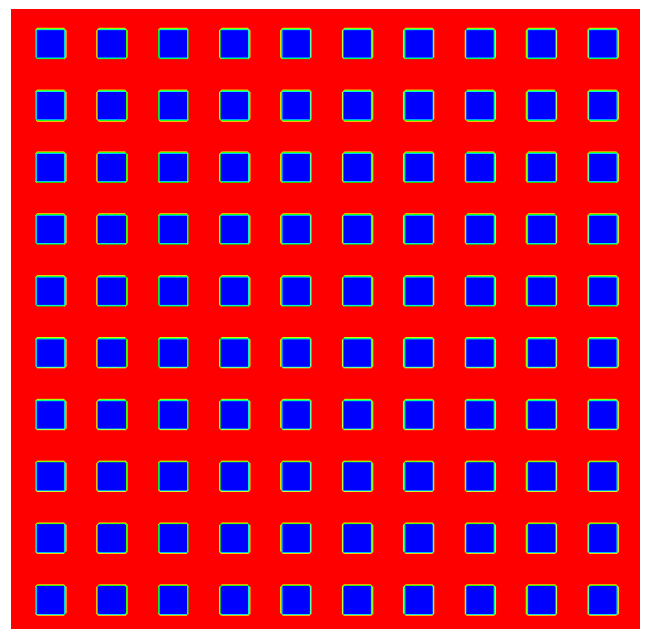

(a) Plan view of the catchment with $10 \times 10$ buildings in in-line arrangement

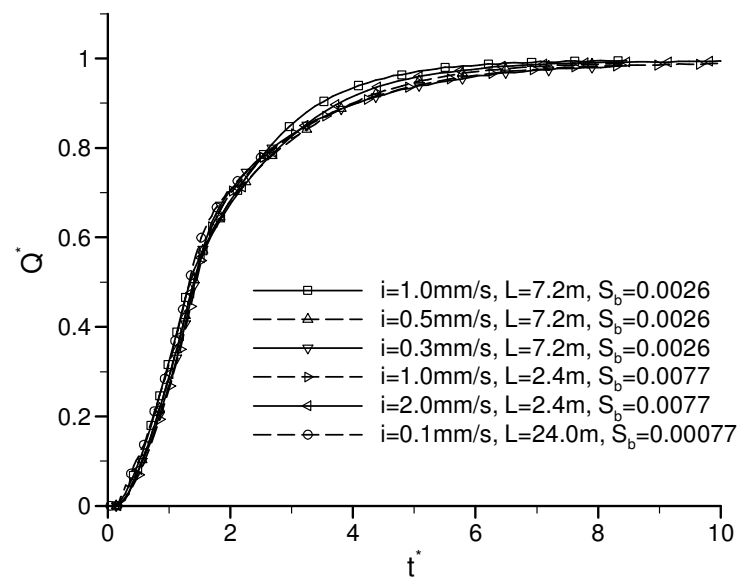

(b) Dimensionless S-curves for a selection of situations with the presence of buildings

Figure 7. S-curves for frictionless catchments with the presence of buildings

From the legend of Fig. 7, it can be seen that the size of the individual buildings specified in the computation is two orders of magnitude smaller than that of the real 
buildings. Buildings of similar sizes have also been used in small-scale laboratory experiments (e.g. Cea et al. 2010). One of the biggest findings of the present study is the method of normalisation that leads to a universal S-curve as shown in Fig. 7(b). The non-dimensional rainfall-runoff relationship is independent of the absolute catchment size, building size, ground slope and rainfall intensity, thus enables the quantitative linkage between the small-scale tests and the real-world phenomena. When an infinitely-large catchment is covered with uniformly-distributed buildings, then what matter to the non-dimensional S-curve are the built-up area ratio and the pattern of the building layout, rather than the absolute size of the individual buildings. Knowing the non-dimensional time of concentration, we can easily convert it into seconds by plugging in the slope and length of a real catchment. Of course, the array of squares can also be regarded as general obstacles in the catchment, but they are called buildings herein to emphasise their relevance to urban flooding.

\subsection{Effect of the configuration of buildings}

\subsubsection{Influence of array dimensions}

First, the influence of the array dimensions on the dimensionless S-curve is investigated. While changing the dimensions of the building array, the ratio of the total built-up area to the catchment area is held at a constant value of $25 \%$. With the increase in the number of buildings, the area of the individual buildings therefore decreases, as can be seen in two examples illustrated in Figures $8(a, b)$. According to the findings established in the previous section, the dimensionless S-curve is not sensitive to the rainfall intensity, catchment size and slope, as long as the catchment is frictionless and the building array has the same pattern and area percentage. Such a conclusion is 
confirmed by undertaking numerical experiments with various building array dimensions, and curves similar to Figure 7(b) have been produced for other array dimensions although they are not shown here.

For the ranges of computational parameters tested, we found that the dimensionless S-curves associated with the following set of parameters roughly lie in the middle of a family of dimensionless S-curves for a given array configuration. Therefore, we only plot the dimensionless S-curves obtained based on the simulations using the following parameters. The rainfall intensity is $0.5 \mathrm{~mm} / \mathrm{s}$; the grid size is $0.03 \mathrm{~m}$, giving the length of the domain to be $7.23 \mathrm{~m}$ in both $x$ and $y$ directions; the slope of the catchment is 0.0026. Figure 8(c) shows the dimensionless S-curves for multiple building arrays, which clearly shows that the larger dimensions of the building array correspond to a more gradual rise of the dimensionless S-curve and thus a longer time of concentration. An explanation for this phenomenon is the increased level of obstruction to the flow when the row and column of the building array increase. As a stream runs down the catchment through buildings, it encounters more frequent sudden expansions and sudden contractions along its passage when the building array dimensions get larger. Therefore, the flow is slowed down and the time of concentration is longer.

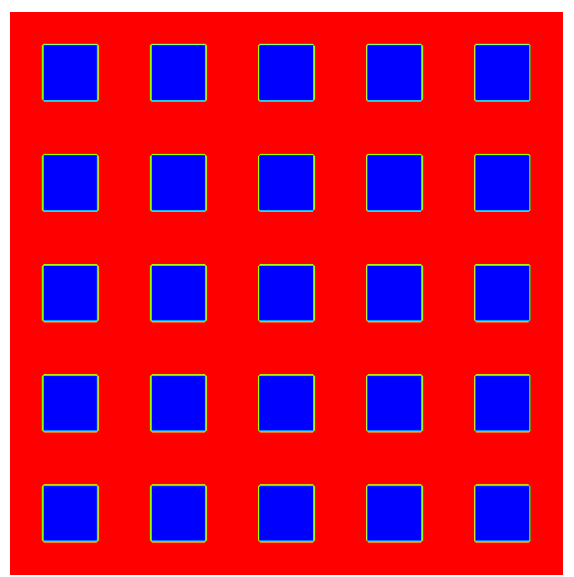


(a) Plan view of the catchment with $5 \times 5$ buildings in in-line arrangement

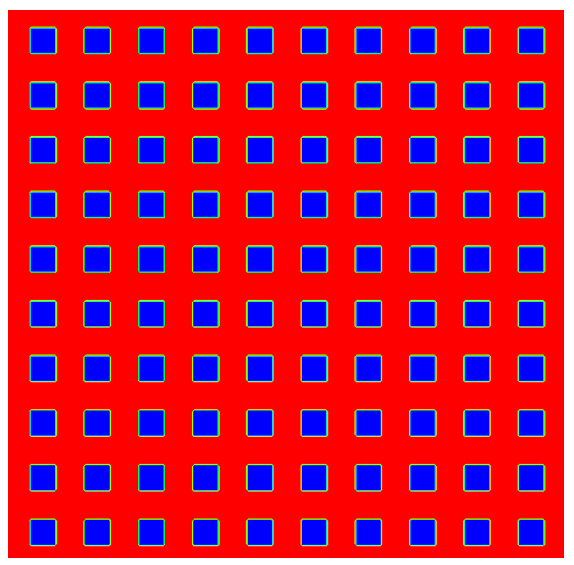

(b) Plan view of the catchment with $10 \times 10$ buildings in in-line arrangement

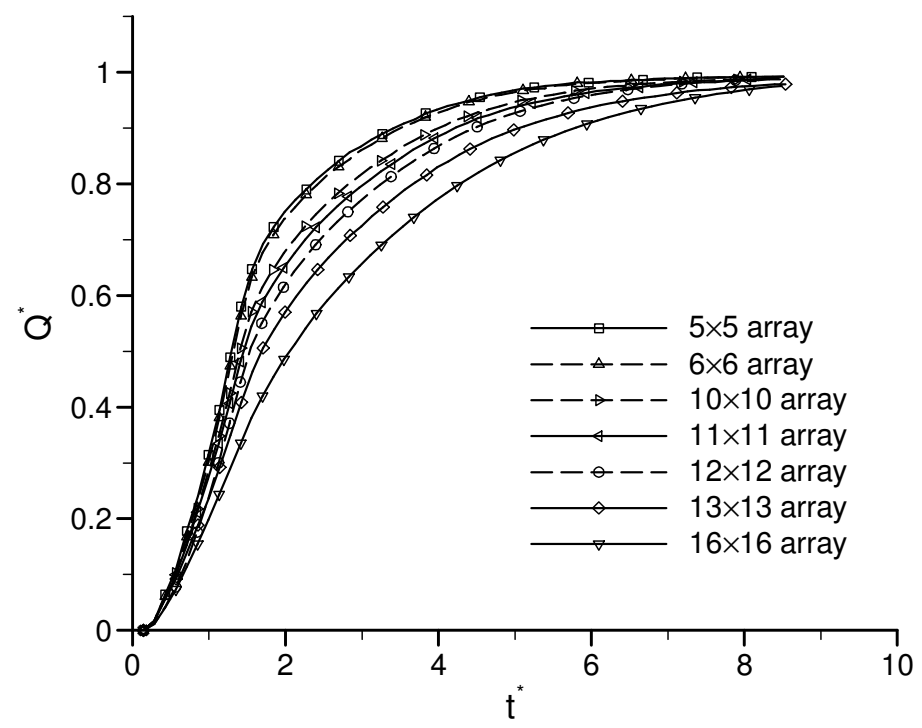

(c) Dimensionless S-curves for different building array dimensions

Figure 8. S-curve dependency on the array dimensions

\subsubsection{Influence of the array layout}

In all the above simulations, the arrays are configured in a way that the buildings directly face one another, which can be referred to as the in-line layout. In this section, the effect of staggering the alternate rows of buildings is investigated. Within an array 
in the staggered arrangement, an individual building directly faces the gaps formed by the adjacent upstream/downstream buildings. Two examples are shown in Figure 9.

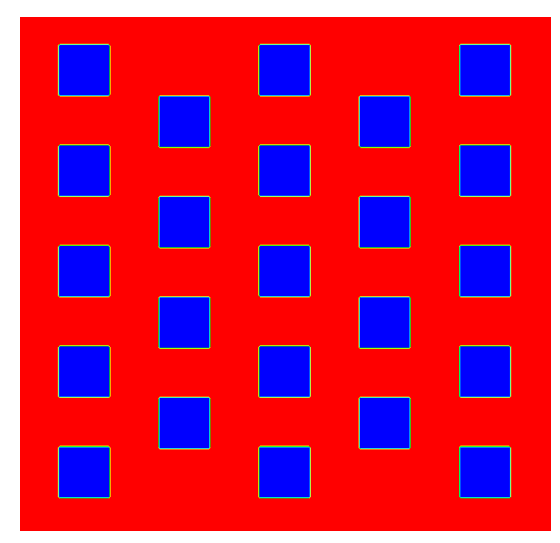

(a) $5 \times 5$ array

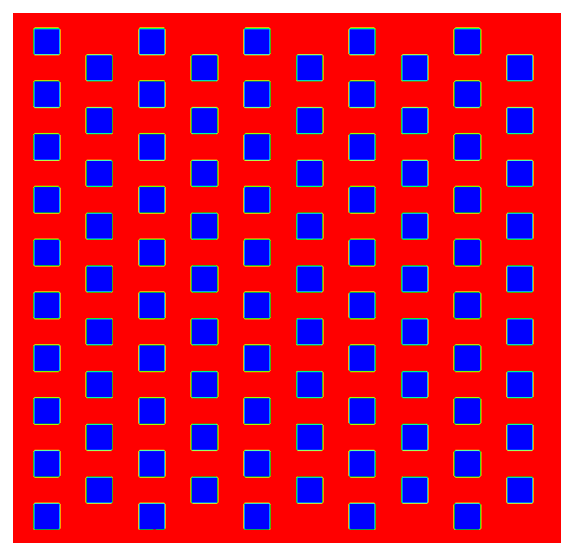

(b) $10 \times 10$ array

Figure 9. Plan view of the catchment with buildings in staggered arrangement

Again, the ratio of the built-up area to the catchment area is kept $25 \%$. A large number of situations have been carried out in the numerical experiments. Only three representative simulations are selected in Figure 10 to illustrate the main findings. In all these three simulations, the rainfall intensity is $1 \mathrm{~mm} / \mathrm{s}$, and the grid size is $0.02 \mathrm{~m}$, giving the length of the domain to be $4.8 \mathrm{~m}$ in both $x$ and $y$ directions. Figure 10 
compares the dimensionless S-curves for the staggered and in-line arrangements. As expected, the staggering clearly increases the time of concentration. Unlike the in-line layout, where straight channels linking the top and bottom of the catchment are established for the runoff, the staggered layout of buildings interrupts these straight water passages. The flow path is thus more sinuous, thus leading to a larger time of concentration. As mentioned previously, the area between the S-curve and the horizontal line representing the constant flow rate at equilibrium is the volume of water that the catchment stores. Corresponding to a longer time of concentration, the catchment with a staggered building array has a larger storage, i.e. large depth, at the equilibrium stage.

According to Figure 10, the dimensionless S-curves for the staggered building arrays in all three array dimensions rise more slowly than their in-line-array counterparts, but to differing degrees. The difference between the S-curves of the two array layouts first expands and then shrinks with the increase of array dimensions. The reason for the relatively small influence of the building layout on the hydrograph for the $5 \times 5$ array may be that the gaps between buildings are so large that the extra obstruction to the flow introduced by the zigzag passage of water is not significant. In this situation, the flow is not significantly influenced by the presence of buildings, and the S-curve is actually similar to that for uniform slopes with no buildings whose dimensionless time scale $t_{50}{ }^{*}$ is around 1.0. When the domain contains a large number of buildings, e.g. the $16 \times 16$ array, the flow passage has very small widths, so the flow through buildings has already experienced much resistance from the presence of buildings. The increased resistance owing to staggering the buildings is only a small proportion of the existing resistance, thus explaining the relatively small sensitivity of the S-curve to the array 
layout. For the $10 \times 10$ array, buildings have a large influence on the flow feature over the domain and staggering the buildings greatly increases the obstruction to the flow. Hence, the rise of the S-curve is significantly slowed when changing the array layout from the in-line arrangement to the staggered arrangement.

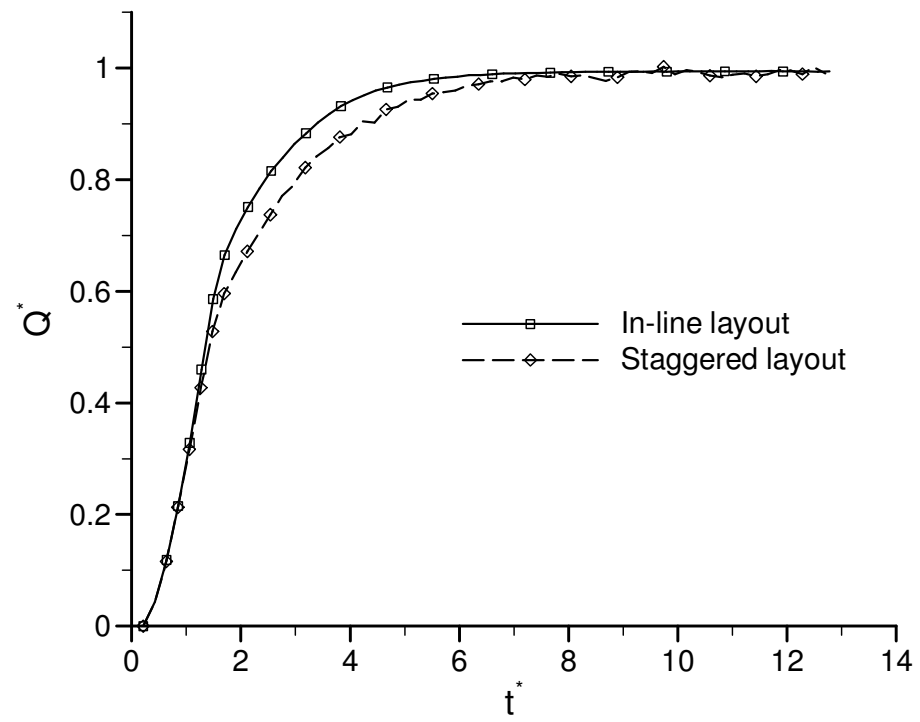

(a) $5 \times 5$ array

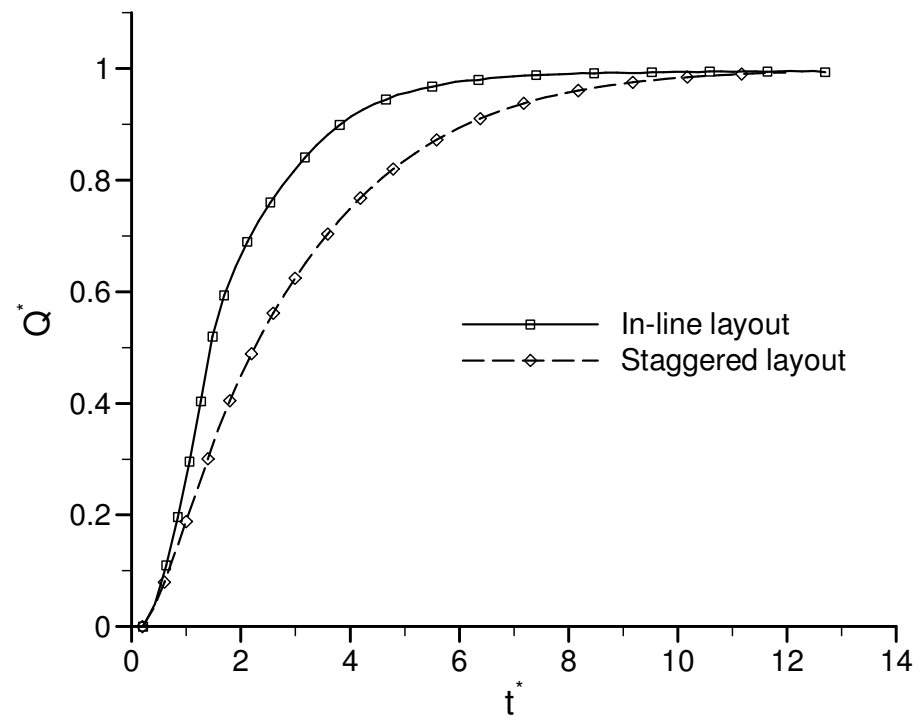

(b) $10 \times 10$ array 


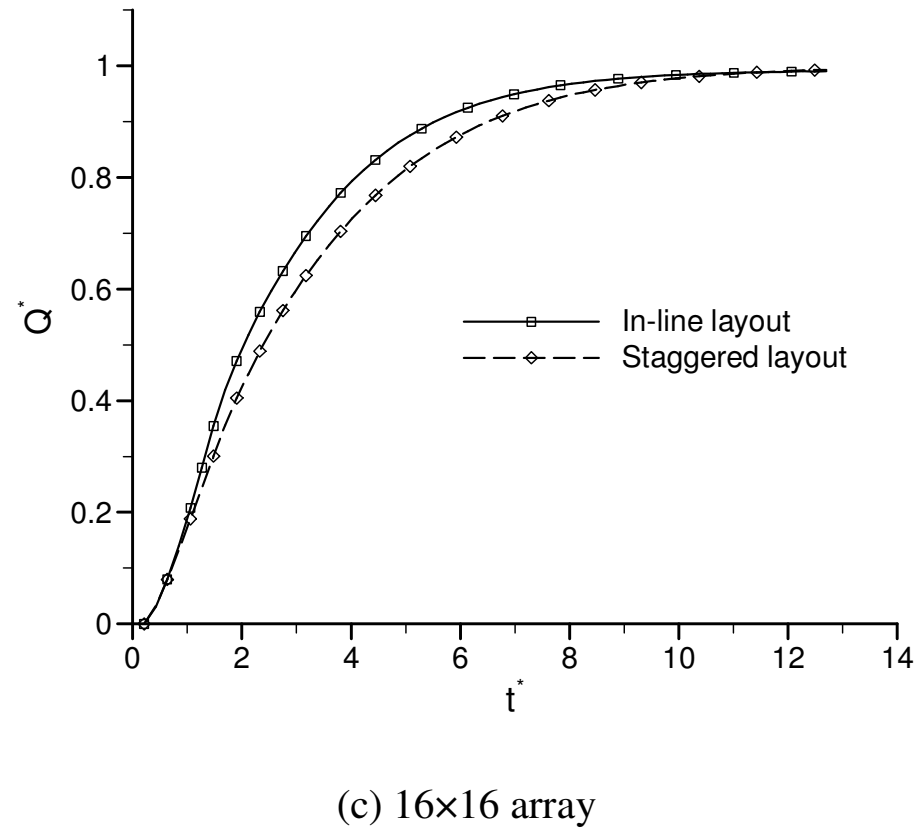

Figure 10. Dimensionless S-curves for different array layouts

\section{Conclusions}

An unsteady 2D hydrodynamic model is applied to study the overland flow phenomena accompanying the rainfall events. The TVD-MacCormack model is shown to accurately solve the fully-dynamic shallow water equations in a wide range of catchment and rainfall conditions. The predicted results agree well with the experimental measurements and analytical solutions. Parametric studies are designed to investigate the influence of buildings on the rainfall-runoff process. In order to draw more generic conclusions, the hydrograph of a catchment is normalised using the nondimensional groups $q /(L \cdot i)$ and $t \sqrt{S_{b} g / L}$. Such a dimensional argument is shown to be valid, as it approximately converges a series of original S-curves to a unique dimensionless S-curve. The time scale of the S-curve rise can be quantified by the dimensionless time of concentration $t_{50}{ }^{*}$, which is around 1.0 for frictionless uniform planes. The inclusion of building arrays increases the value of $t_{50}{ }^{*}$. 
The dependencies of $t_{50}{ }^{*}$ on the building array configuration have been studied systematically. One situation considered is when the total built-up area is kept constant, but the dimensions of the building array and the area of individual buildings are altered. It is found that $t_{50}{ }^{*}$ increases with the increase of the building array dimensions. The other factor considered is the building array layout. It is found that the $t_{50}{ }^{*}$ increases when array layout changes from the in-line pattern to the staggered pattern. However, the difference in the S-curve between the two layouts is insignificant when the array dimensions are either very small or very large, but is significant for the medium array dimensions. These changes of $t_{50}{ }^{*}$ have been explained by examining the characteristics of the extra resistance to the flow due to the presence of buildings.

The crude representation of urban settings in this paper reveals some insights into the buildings' influence on the rainfall-runoff relationship. The results, summarised in a dimensionless manner, are expected to be universal. We are currently investigating more complicated scenarios that include the bed friction and ground infiltration.

\section{Acknowledgements}

Dr. Liang and Prof. Hinkelmann thank the Alexander von Humboldt Foundation for providing the opportunity for their collaboration. Dr. Liang thanks the financial support by the Royal Academy of Engineering (NRCP/1415/97 and ISS151618134). Prof. Xiao and Dr. Chen thank the financial support by the National Natural Science Foundation of China (51450110079) and Chinese Academy of Engineering (2015-ZD-07-04-01).

\section{References}


[1] Caviedes-Voullième D, García-Navarro P, Murillo, J. (2012). Influence of mesh structure on 2D full shallow water equations and SCS Curve Number simulation of rainfall/runoff events. Journal of Hydrology, 448-449: 39-59.

[2] Cea L, Puertas J, Pena L, Garrido M. (2008). Hyrdrological forecasting of fast flood events in small catchments with a 2D-SWE model. Proceedings of the world water congress, Montpellier, France.

[3] Cea L, Garrido M, Puertas J. (2010). Experimental validation of two-dimensional depth-averaged models for forecasting rainfall-runoff from precipitation data in urban areas. Journal of hydrology, 382: 88-102.

[4] Chan Y. (2012). Rainfall-runoff processes in urban environments. MEng thesis. University of Cambridge, U.K., 49pp.

[5] Costabile P, Costanzo C, Macchione F. (2012). Comparative analysis of overland flow models using finite volume schemes. Journal of Hydroinformatics, 14(1): 122-135. [6] Costabile P, Costanzo C, Macchione F. (2013). A storm event watershed model for surface runoff based on 2D fully dynamic wave equations. Hydrological Processes, 27: 554-569.

[7] Di Giammarco P, Todini E, Lamberti P. (1996). A conservative finite elements approach to overland flow: the control volume finite element formulation. Journal of Hydrology 175(1-4): 267-291.

[8] Feng K, Molz GJ. (1997). A 2-D diffusion-based, wetland flow model. Journal of Hydrology, 196: 230-250.

[9] Gottardi G, Venutelli M. (2008). An accurate time integration method for simplified overland flow models. Advances in water resources, 31: 173-180. 
[10] Govindaraju RS, Jones SE., Kavas ML. (1988). On the diffusion wave model for overland flow: 1 Solution for Steep Slopes. Water Resources Research, 24 (5): 734-744, 1988.

[11] Kazezyilmaz-Alhan C, Medina MA. (2007). Kinematic and diffusion waves: analytical and numerical solutions to overland and channel flow. Journal of hydraulic engineering, 133(2): 217-228

[12] Liang D, Falconer RA and Lin B. (2006). Comparison between TVDMacCormack and ADI-type solvers of the shallow water equations. Advances in Water Resources, 29 (12): 1833-1845

[13] Liang D, Falconer RA, Lin B. (2007). Simulation of rapidly varying flow using an efficient TVD-MacCormack scheme. International journal for numerical methods in fluids, 53: 811-826.

[14] Liang D, Wang X, Falconer RA and Bockelmann-Evans BN. (2010). Solving the depth-integrated solute transport equation with a TVD-MacCormack scheme. Environmental modelling \& Software, 25(12):1619-1629.

[15] Liang D, Borthwick AGL and Romer-Lee JK. (2012). Run-up of solitary waves on twin conical islands using a Boussinesq model. Journal of offshore mechanics and arctic engineering, 134(1), Article No. 011102, pp1-9.

[16] Liang D, Xia J, Falconer RA and Zhang J. (2014). Study on tidal resonance in Severn Estuary and Bristol Channel, Coastal engineering journal, 56(1): Article No 1450002, pp1-18.

[17] Moramarco T, Singh VP. (2002). Accuracy of kinematic wave and diffusion wave for spatial-varying rainfall excess over a plane. Hydrological processes, 16: 3419-3435. 
[18] Morgali JR, Linsley RK. (1965). Computer analysis of overland flow. Journal of the Hydraulics Division - ASCE, 91(3): 81-100.

[19] Mügler C, Planchon O, Patin J, Weill S, Silvera N, Richard P, Mouche E. (2011). Comparison of roughness models to simulate overland flow and tracer transport experiments under simulated rainfall at plot scale. Journal of hydrology, 402: 25-40

[20] Schubert JE, Sanders BF. (2012). Building treatments for urban flood inundation models and implications for predictive skill and modelling efficiency. Advances in Water Resources, 41: 49-64.

[21] Simons F, Busse T, Hou J, Özgen I, Hinkelmann R. (2014). A model for overland flow and associated processes within the Hydroinformatics Modelling System. Journal of hydroinformatics, 16(2): 375-391

[22] Tsai WC. (2003). Applicability of Kinematic, Noninertia, and Quasi-Steady Dynamic Wave Models to Unsteady Flow Routing. Journal of Hydraulic Engineering, 129(8): 613-627

[23] Thompson SE, Katul GG, Porporato A. (2010). Role of microtopography in rainfall-runoff partitioning: An analysis using idealized geometry. Water Resources Research, 46 (7), Article No W07520, DOI: 10.1029/2009WR008835

[24] Unami K, Kawachi T, Kranjac-Berisavljevic G, Abagale FK, Maeda S, Takeuchi J. (2009). Case Study: hydraulic modeling of runoff processes in Ghanaian inland valleys. Journal of Hydraulic Engineering, 135(7): 539-553

[25] Woolhiser DA, Liggett JA. (1967). Unsteady, One-Dimensional Flow over a Plane - The rising Hydrograph. Water Resources Research, 3(3): 753-771

[26] Yeh G-T, Shih D-S, Cheng J-R C. (2011). An integrated media, integrated processes watershed model. Computers \& Fluids 45(1): 2-13. 
[27] Zhang W, Cundy TW. (1989). Modeling of two-dimensional overland flow. Water Resources Research 25(9): 2019-2035. 